\section{USE OF A RESPIRATORY FUNCTION MONITOR DURING POSITIVE PRESSURE VENTILATION IN THE DELIVERY ROOM - A RANDOMIZED TRIAL}

G.M. Schmölzer ${ }^{1,2,3,4}$, C.J. Morley ${ }^{3,5}$, O.C. Kamlin ${ }^{5}$, J.A. Dawson ${ }^{3,5,6}$, S. Donath ${ }^{3}$, S. Hooper ${ }^{4}$, P.G. Davis ${ }^{3,5,6}$

${ }^{1}$ Department of Newborn Research, The Royal Women's Hospital, Melbourne, VIC, Australia, ${ }^{2}$ Medical University Graz, Graz, Austria, ${ }^{3}$ Murdoch Children Research Institute, ${ }^{4}$ Monash Institue of Medical Research, ${ }^{5}$ The Royal Women's Hospital, ${ }^{6}$ Obstetrics \& Gynaecology, The University of Melbourne, Melbourne, VIC, Australia

Background and aims: International guidelines recommend that positive pressure ventilation (PPV) in the delivery room (DR) is guided by chest rise and heart rate. Tidal volume $\left(\mathrm{V}_{\mathrm{T}}\right)$ delivery during resuscitation is highly variable and we have shown that resuscitators cannot accurately estimate tidal volume delivery (Schmölzer, ESPR 2009).

To determine if resuscitators can deliver more appropriate tidal volumes and reduce mask leak by using a respiratory function monitor (RFM) during PPV in the DR.

Methods: Infants < 32/40 receiving PPV had a flow sensor placed between the mask and a T-piece. Resuscitators were randomly allocated to have the RFM visible or covered. All resuscitators were trained in the use of the RFM. When the RFM was visible, resuscitators were encouraged to use the display to deliver an expired $V_{\mathrm{T}}$ between $4-8 \mathrm{~mL} /$ $\mathrm{kg}$ with minimal leak. We compared the expired $\mathrm{V}_{\mathrm{T}}$, mask leak, airway pressures, ventilation rate and inflation time between the two groups.

Results: 56 infants were enrolled; mean(SD) gestation 28(2) wks and birthweight 994(331)g, $28(50 \%)$ male and $40(72 \%)$ born by caesarean section. Median(IQR) Apgar-scores at 1 and 5 minutes 5(4-6) and 8(7-8). Mean(SD) expired $V_{T}$ for RFM visible and covered were $6.5(3) \mathrm{mL} / \mathrm{kg}$ and $8.4(3.5) \mathrm{mL} / \mathrm{kg}(p=0.043)$. The mean(SD) facemask leak for the two groups were $39(16) \%$ and $48(22) \%$ $(p=0.13)$. There were no significant differences in ventilation rate, inflation time or airway pressures.

Conclusion: The use of a RFM during PPV in the DR enabled resuscitators to adjust their technique and reduced infants' exposure to potentially harmful tidal volume.

\section{CYCLOSPORINE AND REGIONAL HEMODYNAMICS OF NEWBORN PIGLETS FOLLOWING ASPHYXIA-REOXYGENATION: A DOSE-RESPONSE STUDY}

\author{
R. Gill ${ }^{1}$, N. Manouchehri ${ }^{1}$, J.-Q. Liü ${ }^{2}$, T.-F. Lee ${ }^{2}$, \\ D. Bigam 1 , P.-Y. Cheung ${ }^{1,2}$ \\ ${ }^{1}$ Surgery, ${ }^{2}$ Pediatrics, University of Alberta, \\ Edmonton, $A B$, Canada
}

Introduction: Asphyxiated neonates commonly have multi-organ failure. Cyclosporine has recently been shown to improve systemic hemodynamics, however, its effects on the regional circulation have not yet been studied. We hypothesize that cyclosporine in asphyxiated newborn piglets will dose-dependently improve regional hemodynamics and oxygen metabolism.

Methods: Piglets (1-4 days-old) were acutely instrumented for continuous monitoring of common carotid (CA), superior mesenteric (SMA) and renal (RA) arterial flows. After stabilization, normocapnic alveolar hypoxia (10-15\% oxygen) was instituted for $2 \mathrm{~h}$ followed by reoxygenation with $100 \%$ oxygen for $0.5 \mathrm{~h}$, then $21 \%$ for $3.5 \mathrm{~h}$. Piglets were blockrandomized to receive one of three cyclosporine intravenous boluses $(2.5,10$ or $25 \mathrm{mg} / \mathrm{kg}$ ) or placebo (normal saline, control) after 5 minutes of $100 \%$ reoxygenation ( $n=8 /$ group). Blood samples were collected for co-oximetry analysis and oxygen transport calculation. Statistical analysis was performed using ANOVA.

Results: All piglets had decreased regional blood flow (CA 52-64\%, SMA 34-56\%, RA 25-35\% compared to respective baseline), hypotension (mean arterial pressure $30 \mathrm{mmHg}$ ) and acidosis $(\mathrm{pH}$ 7.04 ) at $2 \mathrm{~h}$ of hypoxia. Cyclosporine (2.5 and $10 \mathrm{mg} /$ $\mathrm{kg}$ ) treatment at reoxygenation caused dose-related improvements in SMA flow and oxygen delivery. Cyclosporine $(10 \mathrm{mg} / \mathrm{kg})$ significantly increased RA flow and oxygen delivery ( $P<0.05$ vs. controls). While CA flows were not different among groups, cyclosporine $(25 \mathrm{mg} / \mathrm{kg})$ had significantly higher CA oxygen delivery than controls.

Conclusion: In newborn piglets following asphyxiareoxygenation, post-resuscitation administration of cyclosporine caused differential and dose-related improvements of regional perfusion. 